\title{
Characterization of nanoparticle mediated laser transfection by femtosecond laser pulses for applications in molecular medicine
}

\author{
Markus Schomaker ${ }^{1 *}$, Dag Heinemann', Stefan Kalies', Saskia Willenbrock², Siegfried Wagner², Ingo Nolte², \\ Tammo Ripken', Hugo Murua Escobar ${ }^{2,3}$, Heiko Meyer $^{1,4}$ and Alexander Heisterkamp ${ }^{1,5}$
}

\begin{abstract}
Background: In molecular medicine, the manipulation of cells is prerequisite to evaluate genes as therapeutic targets or to transfect cells to develop cell therapeutic strategies. To achieve these purposes it is essential that given transfection techniques are capable of handling high cell numbers in reasonable time spans. To fulfill this demand, an alternative nanoparticle mediated laser transfection method is presented herein. The fs-laser excitation of cell-adhered gold nanoparticles evokes localized membrane permeabilization and enables an inflow of extracellular molecules into cells.

Results: The parameters for an efficient and gentle cell manipulation are evaluated in detail. Efficiencies of 90\% with a cell viability of $93 \%$ were achieved for siRNA transfection. The proof for a molecular medical approach is demonstrated by highly efficient knock down of the oncogene HMGA2 in a rapidly proliferating prostate carcinoma in vitro model using siRNA. Additionally, investigations concerning the initial perforation mechanism are conducted. Next to theoretical simulations, the laser induced effects are experimentally investigated by spectrometric and microscopic analysis. The results indicate that near field effects are the initial mechanism of membrane permeabilization.

Conclusion: This methodical approach combined with an automated setup, allows a high throughput targeting of several 100,000 cells within seconds, providing an excellent tool for in vitro applications in molecular medicine. NIR fs lasers are characterized by specific advantages when compared to lasers employing longer (ps/ns) pulses in the visible regime. The NIR fs pulses generate low thermal impact while allowing high penetration depths into tissue. Therefore fs lasers could be used for prospective in vivo applications.
\end{abstract}

Keywords: Laser transfection, Plasmonics, Nanoparticles, Permeabilization mechanisms, siRNA, Gene delivery

\section{Background}

The direct modulation of gene expression is essential to establish therapeutic approaches in molecular medicine. Additionally to the development of therapies on the molecular level, the evaluation of target genes as therapeutic agents by combining the technology of RNAi and high throughput screenings is of major interest [1-3].

A major challenge in molecular medicine is the efficient, non-toxic and cell type independent transfection of cells in high throughput. In general a very effective manipulation strategy to achieve this is the transduction

\footnotetext{
* Correspondence: m.schomaker@lzh.de

'Department of Biomedical Optics, Laser Zentrum Hannover, Hollerithallee 8 , 30419 Hannover, Germany

Full list of author information is available at the end of the article
}

of cells via viral vectors. However, despite of the high efficiency this method bears high biological risk as integrational mutagenesis [4]. Alternative existing non-viral transfection methods show specific advantages and disadvantages. Transfection with lipid based reagents is often applied in high throughput assays but this method is cell type dependent and occasionally inefficient, especially for primary- and stem cell transfection [5]. Due to the difficulties in transfection of these cells, the commonly employed manipulation methods are either electroporation or nucleofection [6,7]. Unfortunately, these methods affect cell viability which is crucial when handling sensitive cells. Consequently in this manipulation it is essential to achieve a balance between transfection efficiency and methodical toxicity. Electroporation and 
nucleofection can also be utilized for high throughput assays, but these physical techniques remain usually limited to well plates with low well numbers being additionally cost ineffective [8].

In order to address these challenges methodicaly, a variety of optical transfection techniques have been developed based on pulsed as well as continuously emitting lasers [9-13]. None of these techniques fulfills the requirements of an efficient and low-toxic transfection method combined with high throughput. Accordingly, there is no laser based technique currently established, that allows routinely laboratory or clinical use. A promising tool for molecular medical applications is the nanoparticle mediated laser transfection using a microchip laser emitting ps laser pulses with a resonant wavelength of $532 \mathrm{~nm}[14,15]$. Herein, gold nanoparticle (AuNP) labeled cells are irradiated with a weakly focused laser beam. This method allows targeting many cells simultaneously, ensuring high throughput while maintaining a high spatial selectivity. Additionally, this physical method using resonant laser pulses is very promising for the manipulation of a variety of cell types.

By applying off-resonant fs laser pulses, the transfection of hematopoietic stem cells (CD34+) can be achieved [16]. Here, the excitation of the membrane adhered AuNP with the incident laser light leads to plasmon resonances which increase the absorption and scattering cross section of the AuNP by several orders of magnitude. When the AuNP is irradiated at a resonant wavelength, the laser energy is absorbed leading predominantly to thermal effects and changes in the particles morphology [15,17]. Using near infrared (NIR) femtosecond (fs) laser systems, off-resonant AuNP excitation can be achieved [18]. At this wavelength the absorption and therefore the thermal impact is reduced and the incident light is scattered into the near field of the particle. Due to this "nanolens" effect, an enhancement of the electric field in the near field takes place [19]. If the AuNP is adhered to the cell membrane, the field enhancement can initiate a spatially confined membrane permeabilization [18]. In proof of principle experiments we could show the possibility to perforate the cell membrane using off resonant $800 \mathrm{~nm}$ fs laser pulses to deliver fluorescent labeled small interfering RNA (siRNA) and plasmid DNA (pDNA) into cells [20,21]. In another fs based study, a DNA-transfection rate of $23 \%$ using a melanoma cell line was stated and plasma induced nanocavitation is supposed as the membrane permeabilization effect [22]. The advantage of NIR wavelengths located in the "diagnostic window" regime of the electromagnetic spectrum results in higher penetration depths into biological tissue which might allow in vivo applications [23]. Furthermore, the low absorption cross section in the NIR reduces the risk of thermal induced AuNP fragmentation.

Within this work, microscopic analyses were performed to visualize the nanoparticle-cell membrane interaction, such that the co-incubation time for membrane permeabilization and the fundamental binding mechanism could be evaluated. To achieve an efficient uptake of extracellular molecules at high cell viabilities, a detailed parameter evaluation for a transient cell membrane permeabilization was performed. Different radiant exposures, scanning velocities of the laser spot, particle concentrations and particle sizes were applied to determine optimized permeabilization parameters. Additionally, the cell viability on a time scale up to $72 \mathrm{~h}$ after laser exposure and AuNP incubation was evaluated. The optimized parameters were used to evaluate the siRNA transfection efficiency, cell viability and functional oncogene knockdown in a cancer cell line. Due to the scanning method (Figure 1) and the automated setup, a high throughput is achieved and thus it is possible to handle all kinds of well plates within several minutes. Additionally to the manipulation experiments, the effects involved in the permeabilization process are investigated by temperature and near field simulations and a particle fragmentation study to further analyze the excitation of AuNP and the perforation mechanisms. The results indicate that both, near field and
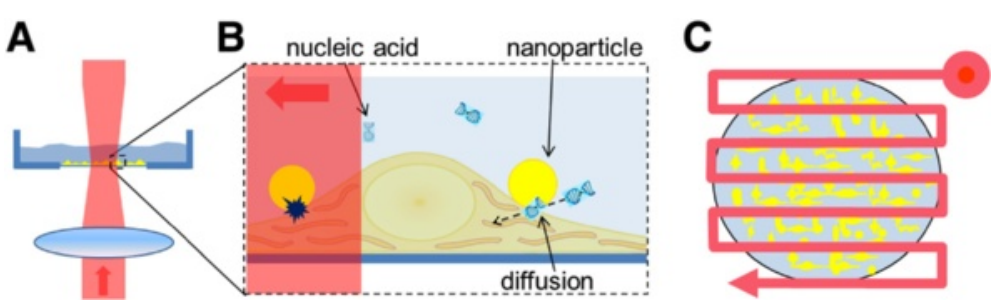

Figure 1 Principle of AuNP mediated laser cell membrane permeabilization. Spherical AuNP were incubated with the cells to allow sedimentation of the particles onto the cell membrane. Prepared samples were placed on an automatized stage to move selected wells of a well plate into the laser focus. Selected wells were completely irradiated by a raster shaped pattern with an inter line distance of $55 \mu \mathrm{m}(1 / 3$ of the laser diameter). A) Side view: the laser beam is weakly focused on the dish bottom where the AuNP labeled cells are located. B) Sketch of manipulation principle: AuNP are in contact with the cell membrane and irradiated by fs-laser pulses (left side). The interaction of the laser pulses with membrane adhered AuNP induces plasmon mediated effects which result in a transient enhanced permeability of the cell membrane. Through this permeabilization, extracellular molecules can cross the cell membrane and diffuse into the cytoplasm (right side). C) By applying a meander shaped scanning pattern, a high number of cells can be treated. 
heating effects contribute to the mechanism of nanoparticle mediated membrane permeabilization in the fs regime.

\section{Results}

\section{Interaction of cells with gold nanoparticles}

Time lapse multiphoton microscopy was employed to monitor the incubation process. As shown in Figure 2A, bright spots, identified as the luminescence of the AuNP, are visible at the cell membrane after $3 \mathrm{~h}$ of incubation. Images which were taken at shorter incubation times show no spots or marginal changes in the background brightness. Increasing the incubation time from 3 to $5 \mathrm{~h}$ resulted slightly brighter luminescence. Within 5 to $7 \mathrm{~h}$ of co-incubation, the number and brightness of the AuNP signal saturated. The AuNP luminescence was still visible after washing, indicating that the particles remained adhered to the cell membrane.

Scanning electron microscopy (SEM) and environmental scanning electron microscopy (ESEM) provided detailed information about the attachment and distribution of the AuNP at the cell membrane after co-incubation and several washing steps (Figure 2B, C). The results show a loose dispersion of AuNP after $1 \mathrm{~h}$ of incubation. The particles were located at the culture dish bottom and on the cell membrane. By increasing the incubation time to more than 3 hours, the particles started to aggregate at the cell membrane. After an incubation time of $5 \mathrm{~h}$, no further increase could be observed. Depending on the location of the particles, some of the particles appeared brighter than others. At higher magnifications, as visible in Figure $2 \mathrm{C}$, some particles were located on the cell membrane (solid ellipse Figure $2 \mathrm{C}$ ) and some were started to be endocytosed (dashed ellipse Figure 2C), which is demonstrated by the cell membrane covered particles. Based on this we defined an incubation time of $3 \mathrm{~h}$ for our gold nanoparticle mediated laser transfection. Within this time a sufficient number of particles adhere to the cell membrane to induce membrane permeabilization. The number of particles at the cell membrane was counted using ESEM images of ZMTH3 cells taken after $3 \mathrm{~h}$ of incubation. An incubation concentration of $11 \mu \mathrm{g} / \mathrm{ml}$ was applied which represents the optimal concentration for cell manipulation. On average $164 \pm 50$ particles at the membrane of a single cell were counted.

\section{Evaluation of efficient and gentle cell manipulation parameters}

To evaluate the optimal process parameters for an efficient and gentle cell manipulation, the cells were treated with different parameters in the presence of $10 \mathrm{kDa}$ FITC labeled dextran and the corresponding fluorescence level was determined. As an indicator for viability, the respective metabolic activities of the manipulated cells were measured after laser treatment using an fluorescence based assay (Qblue). An efficiency ratio of the used parameters was evaluated as the normalized ratio of FITC fluorescent level and viability. The purpose was to optimize the parameters for later transfection experiments and to get an overview of the influence of the different parameters. It was not intended to determine absolute transfection efficiencies.

The influence of the scanning velocity on the molecular uptake targeting ZMTH3 cells is shown in Figure 3A. At a fixed scanning velocity, AuNP size and AuNP concentration of $11 \mu \mathrm{g} / \mathrm{ml}$, the FITC fluorescence level increased with increasing radiant exposure. The highest efficiency ratio was found at $80 \mathrm{~mJ} / \mathrm{cm}^{2}$ for a scanning velocity of $50 \mathrm{~mm} / \mathrm{s}$. With higher radiant exposures, the

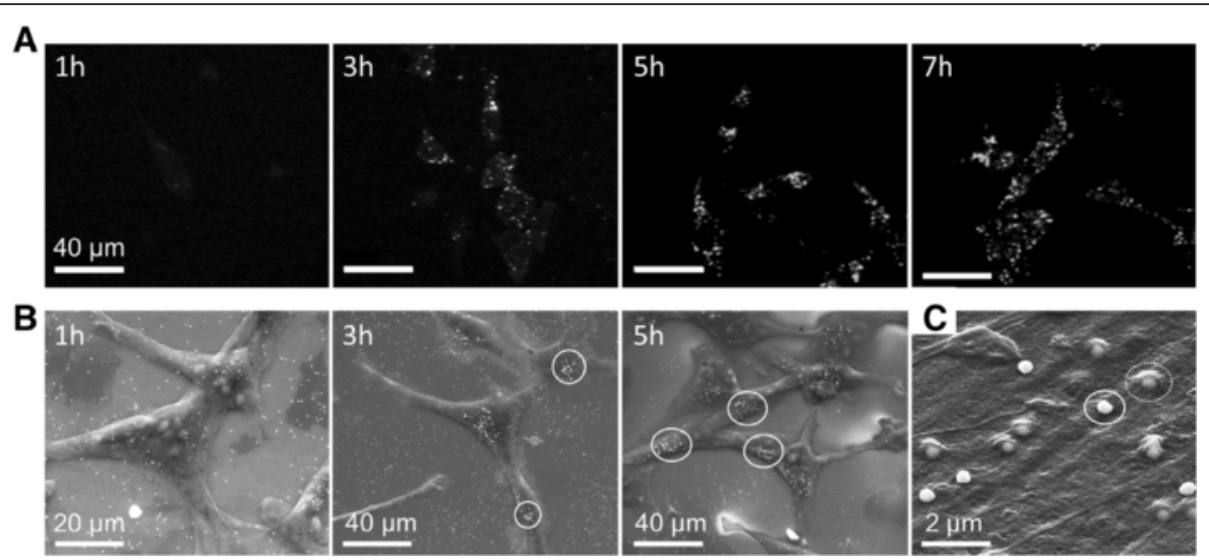

Figure 2 Nanoparticle - cell interaction. A) Time lapse multiphoton microscopy of granulosa cells with $150 \mathrm{~nm}$ particles after $1 \mathrm{~h}, 3 \mathrm{~h}, 5 \mathrm{~h}$ and $7 \mathrm{~h}$ of co-incubation. B) ESEM and C) SEM images of ZMTH3 cells after different incubation times with $200 \mathrm{~nm}$ gold particles. B) ESEM images: After $1 \mathrm{~h}$ a loose dispersion of particles is visible. After $3 \mathrm{~h}$ the AuNP started to aggregate (ellipse). The formation of particle clusters at the membrane can be observed after 5 h. C) SEM image in a higher magnification: After an incubation time of 3 h, particles are either on the cell membrane (solid ellipse) or covered by the membrane (dashed ellipse) [24]. 


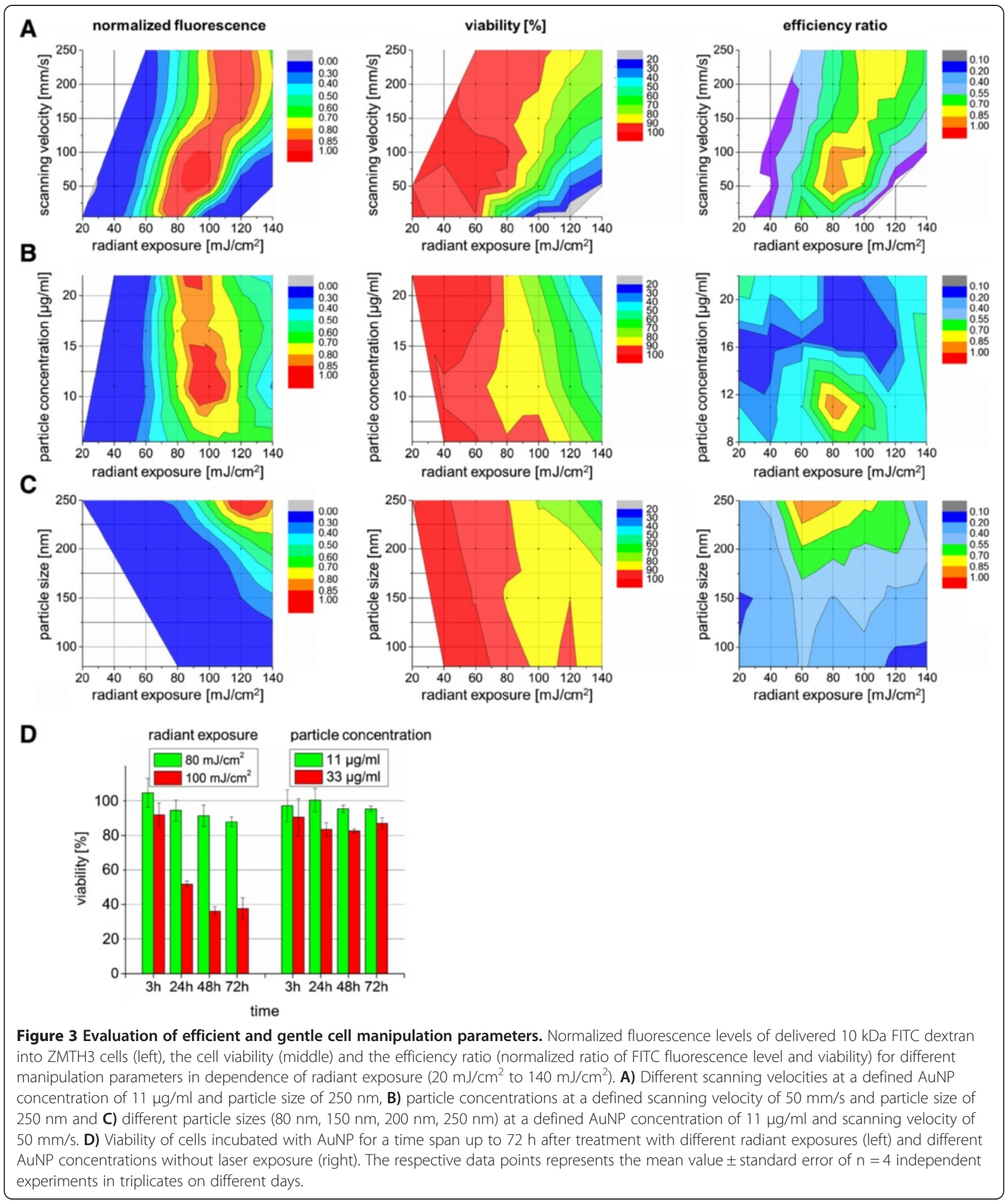

efficiency ratio decreased due to a loss in cell viability as a consequence of an irreversible damage of the cell membrane and/or the ablation of the cells from the glass bottom. Varying the AuNP concentration (Figure 3B), the highest efficiency ratio was reached at a concentration of
$11 \mu \mathrm{g} / \mathrm{ml}\left(6.3 \mu \mathrm{g} / \mathrm{cm}^{2}\right)$ and a radiant exposure of $80 \mathrm{~mJ} /$ $\mathrm{cm}^{2}$. When exceeding the threshold of $11 \mu \mathrm{g} / \mathrm{ml}$ the efficiency ratio dropped most likely due to many induced pores which consequently results in irreversible cell damage. 
A further parameter impacting the efficiency ratio is the particle size (Figure 3C). A higher efficiency ratio was reached with an increase of particle size. Up to a particle size of $150 \mathrm{~nm}$ no efficient permeabilization occurred. Using larger particle sizes, the efficiency ratio peaked at a radiant exposure of $60 \mathrm{~mJ} / \mathrm{cm}^{2}$ for $200 \mathrm{~nm}$ and $60-80 \mathrm{~mJ} / \mathrm{cm}^{2}$ for $250 \mathrm{~nm}$ particles before the efficiency ratio dropped due to laser induced cell damage.

\section{Monitoring of the exposure effects on cell viability}

The cell viability after performing permeabilization experiments at different radiant exposures and a fixed AuNP concentration of $11 \mu \mathrm{g} / \mathrm{ml}$ was followed up to $72 \mathrm{~h}$. As presented in Figure 3D (left), the cell viability remained above $80 \%$ using radiant exposures up to $80 \mathrm{~mJ} / \mathrm{cm}^{2}$. For a higher radiant exposure of $100 \mathrm{~mJ} / \mathrm{cm}^{2}$ the cell viability strongly decreased to $40 \%$.

The incubation of cells with AuNP at a concentration of $11 \mu \mathrm{g} / \mathrm{ml}$ for three hours without laser treatment did not show any pronounced effect on the viability for a time period of $72 \mathrm{~h}$. Even the tripling of the AUNP incubation concentration to $33 \mu \mathrm{g} / \mathrm{ml}$ leads only to a slight decrease to $80-85 \%$ in cell viability. This negative effect on cell viability is likely to be caused by the residues of chloroauric acid used while particle manufacture.

Based on the presented results in Figure 3, the optimal parameter for an efficient cell permeabilization and tolerable cell loss is to a radiant exposure of $80 \mathrm{~mJ} / \mathrm{cm}^{2}$, a particle size of $250 \mathrm{~nm}$ and an AuNP concentration of $11 \mu \mathrm{g} / \mathrm{ml}$.

\section{Nanoparticle mediated laser transfection}

The evaluated parameters allowing an efficient and gentle cell permeabilization were used for cell transfection experiments. In Figure 4A the cell density is visualized by Hoechst 33342 nuclei staining. The successful transfection of CT1258 and ZMTH3 cells with an Alexa Fluor 488 labeled siRNA was performed using the optimized parameter (Figure 4B). Neither in the negative control (with siRNA, no laser treatment (Figure 4C)) nor in the AuNP control (with siRNA and AuNP incubation (Figure 4D)) a fluorescent signal was detected. Within the laser control (with siRNA and laser treatment, no AuNP) a weak fluorescence in individual cells was detected (Figure 4E). For CT1258 cells, a transfection efficiency of $85 \% \pm 9$ was evaluated using fluorescence microscopy. Here the fraction of necrotic cells was $3 \%$. Flow cytometry analysis of ZMTH3 cells revealed a transfection efficiency of $90 \%$ and a cell viability of $93.5 \%$. A significant difference (* $\mathrm{p} \leq 0.05)$ was found between the siRNA samples and the native cells. The percentage of apoptotic cells was $2.15 \%$ and $5 \%$ for necrotic cells (Figure 4F).
In order to evaluate a potential gene therapeutic approach, functional siRNAs were used in a proof of principle experiment using high cell numbers. For HMGA2 (high mobility group AT-hook 2) gene knock down experiments the canine HMGA2 overexpressing cell line CT1258 [25] was transfected with four different anti-HMGA2 siRNAs complementary to the $3{ }^{\prime}$ untranslated region of the HMGA2 mRNA and one non-sense scrambled siRNA. Due to the lack of reliable evaluated canine antibodies against the protein and thus potential unspecific cross reactions we opted for quantitative real-time PCR as detection method. This technique allows to measure the canine HMGA2 mRNA expression quantitatively.

The relative $H M G A 2$ mRNA expression was analyzed $48 \mathrm{~h}$ after treatment via one step quantitative real time PCR (qRT-PCR) analysis (Figure 4G). The HMGA2 expression was quantified relative to the housekeeping gene Beta-actin (ACTB), the non-treated cells were used for calibration (reference value $=1$ ). In all samples treated with HMGA2 specific siRNAs in combination with the laser manipulation suppression of $H M G A 2$ could be observed. The highest suppression was induced by using the siRNA 1 and 2. For the siRNA 1 and 3, the gene knock down was significant compared to native cells ( $\mathrm{p}$-values < 0.05). In the control samples, no HMGA2 gene knock down could be observed. A slight increase was found for the scrambled siRNA, potentially resulting from off-target effects. No significant difference between the control samples and native cells was observed.

\section{Characterization of the nanoparticle mediated membrane permeabilization mechanism}

In this section we describe different experiments to address the mechanisms involved in membrane permeabilization focusing on the parameters allowing an efficient and gentle cell manipulation.

Simulations of the near field distribution of the electric field at an incident wavelength of $796 \mathrm{~nm}$ for $80 \mathrm{~nm}$ and $250 \mathrm{~nm}$ particles are shown in Figure 5A and B, mapping the field-enhancement at the particles. For larger particles the dipole emission is distorted due to multipole oscillations within the sphere [17]. The enhancement factors of the different AuNP sizes are presented in Figure 5C (left y axis). For the used particles the highest field enhancement is reached for $150 \mathrm{~nm}$ particles. Here the near field is about 10 times higher than the incident field. For the 200 $\mathrm{nm}$ and $250 \mathrm{~nm}$ particles, the average enhancement is at 6.6 and 4.9, respectively. Furthermore, the near field volume is increasing with an increasing particle size (Table 1) and thereby the interaction zone of the near field with the membrane. This could be a reason for the increasing permeabilization efficiency at larger particle sizes shown in Figure 3C. 


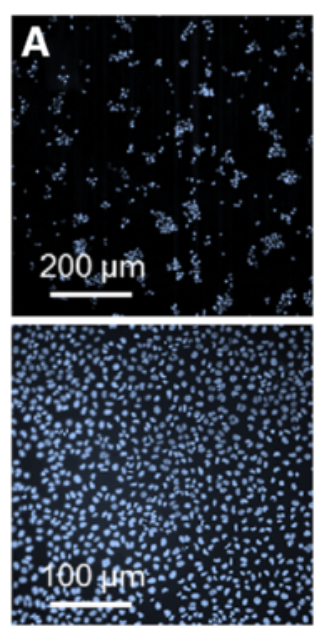

$\mathbf{F}$

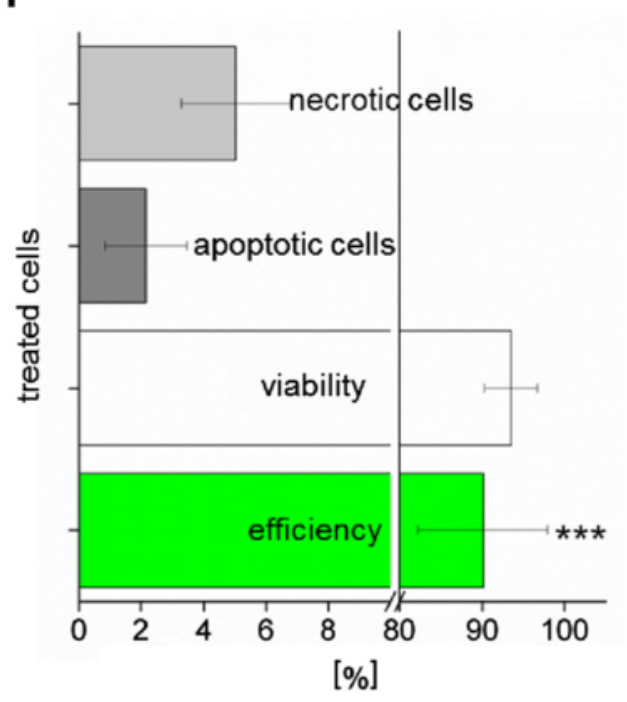

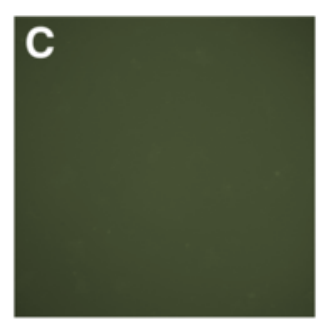
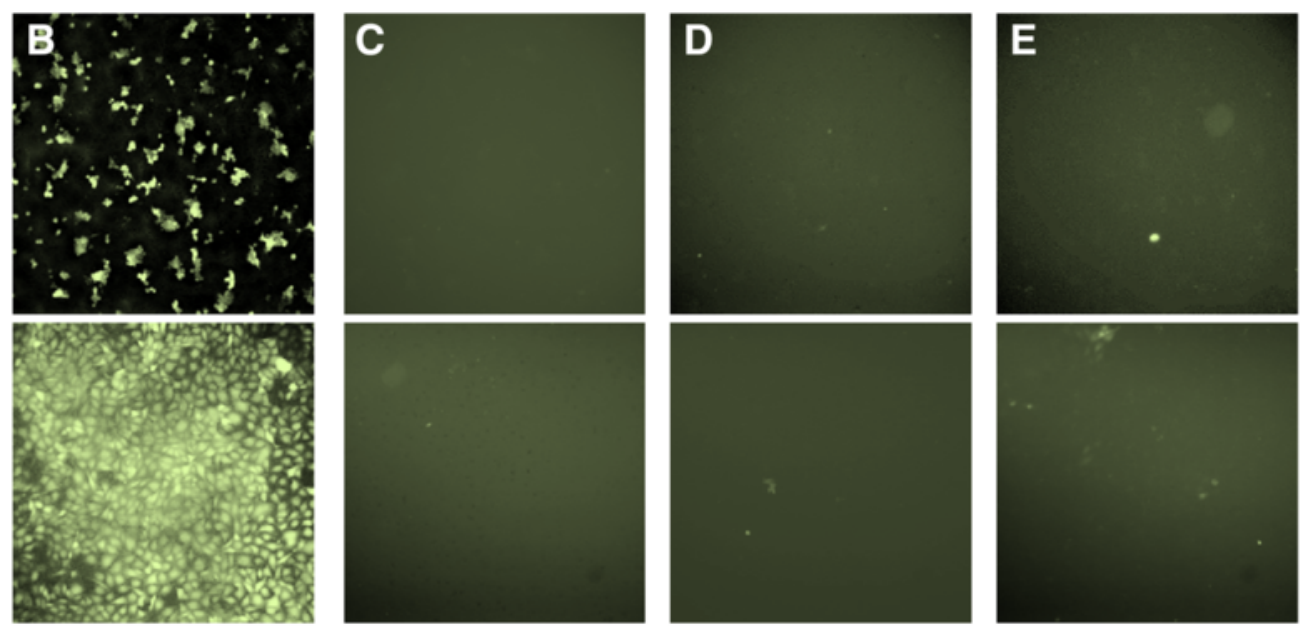

G

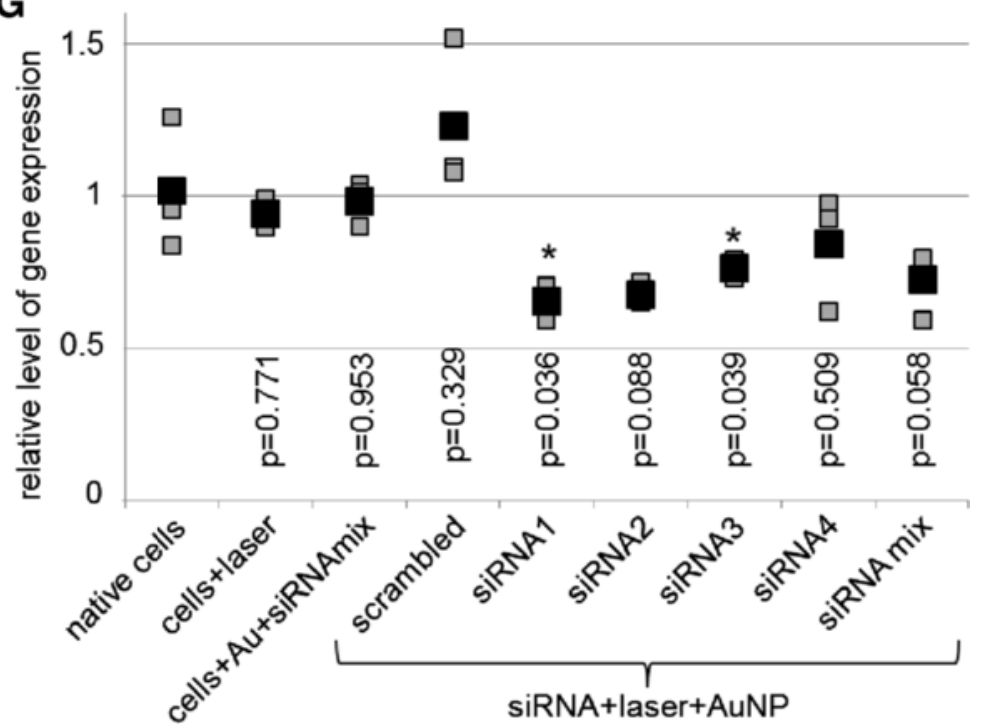

Figure 4 siRNA transfection. A-E) Microscopic images of treated cells (upper row CT1258 cells, bottom row ZMTH3 cells): A) The fluorescent images of Hoechst stained cell nuclei shows cell density. B) An Alexa fluor 488 labeled siRNA was efficiently transfected into the cells. C) The incubation of cells with siRNA (negative control) and D) the fluorescent image of AuNP labeled cells (AuNP control) show no siRNA uptake. E) A slight fluorescence signal in the laser control is detected when native cells are irradiated with the laser in the presence of the fluorescent siRNA. F) The flow cytometric analysis of siRNA transfected cells shows an efficiency of about $90 \%$ and a cell viability of $93 \%$. Every data point represents the mean value \pm standard error of $n=3$ independent experiments in triplicates on different days. G) Real-time PCR analysis: Transfection of CT1258 cells results in HMGA2 gene knock down using different HMGA2 specific siRNAs (real-time PCR analyses were performed in triplicates). The black boxes represent the mean values of the qRT-PCR analysis and the grey boxes depict each of the three single measurements.

The evaluated enhancement factors and the applied intensity were used to calculate the near field intensity (Figure $5 \mathrm{C}$ (right $\mathrm{y}$ axis)). The values of the near field intensities of all particle sizes are below the threshold of an optical breakdown (LIOB) in water, which is $6 \times 10^{12} \mathrm{~W} / \mathrm{cm}^{2}$ for the used wavelength and pulse duration [26]. The highest near field intensity is reached for $150 \mathrm{~nm}$ particles which is close to the LIOB threshold. Intensities below the LIOB threshold in the low density plasma regime can lead to nonlinear effects like multiphoton ionization and avalanche-ionization. This might lead to the permeabilization of the cell membrane [14,22,27].
The accumulation of single pulses can induce the dissociation of biological molecules by forming reactive oxygen species (ROS) which results in membrane permeabilization [27]. Here, the threshold pulse energy $E_{N}$ depends on the number of pulses (Equation (1)) [14,27].

$$
E_{N}=E_{1} \cdot N^{-1 / k}
$$

Where $E_{1}$ describes the threshold energy of a single pulse, $\mathrm{N}$ is the number of pulses and $\mathrm{k}$ the accumulation strength [28]. 

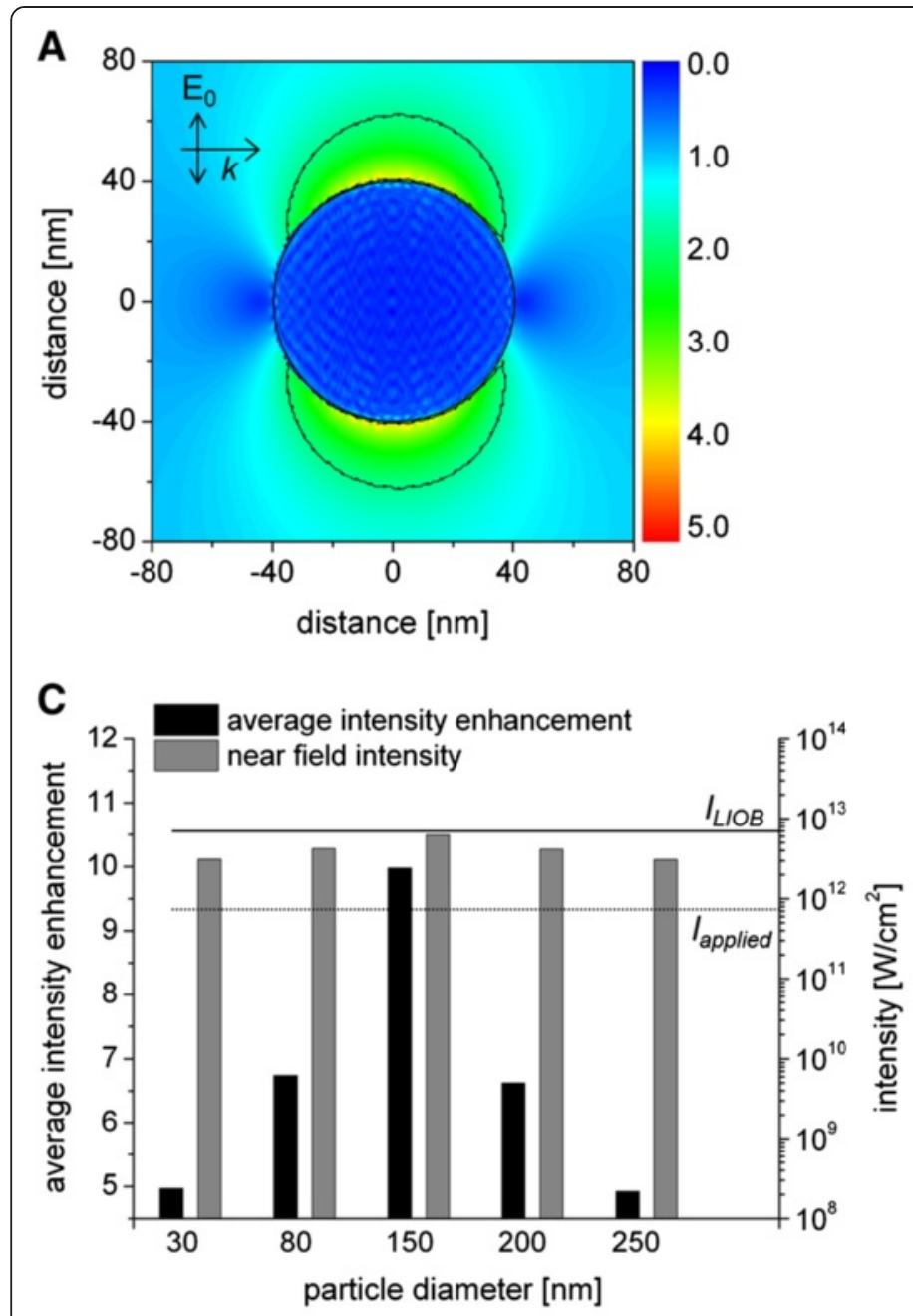

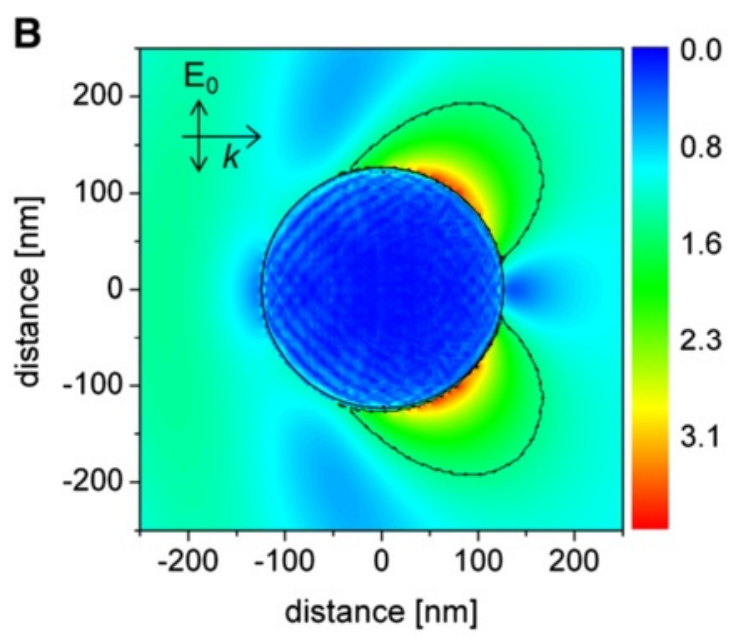

D

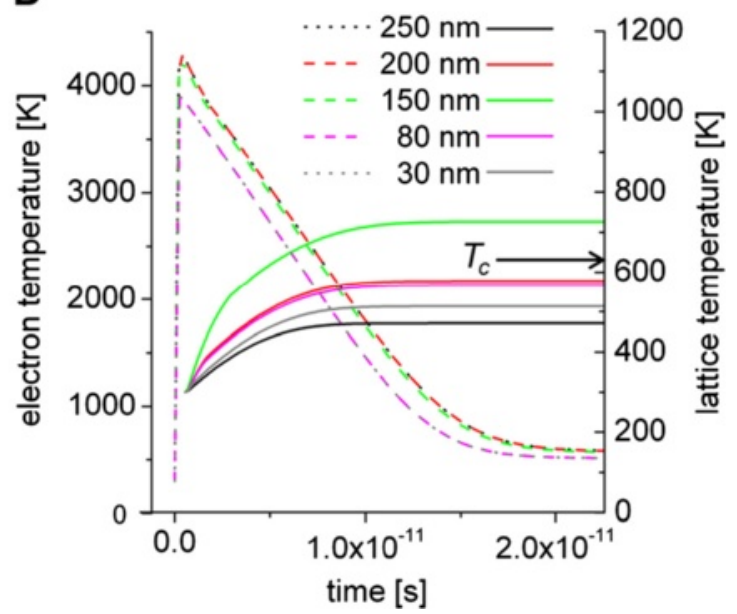

Figure 5 Particle - laser interaction. Particle excitation after interaction of a $798 \mathrm{~nm}$ laser pulse with duration of $120 \mathrm{fs}$ and a radiant exposure of $80 \mathrm{~mJ} / \mathrm{cm}^{2}\left(I=6.26 \times 10^{11} \mathrm{~W} / \mathrm{cm}^{2}\right)$. A) Map of the near field enhancement factor ( $\left.\eta=E / E 0\right)$ around an $80 \mathrm{~nm}$ particle and B) $250 \mathrm{~nm}$ particle. The dashed lines indicate the areas were the enhancement factor is higher than 1/e. The incident field Eo propagates along the $x$ axis. C) Calculations of the near field enhancement around AuNP (left y axis) and the near field intensity (right y axis) for different AuNP sizes. Additionally the threshold for the applied intensity (dashed line) and the calculated intensity for LIOB using a NA 1.3 focused laser spot (solid line) is drawn. D) Evolution of the electron- (dashed lines) and lattice temperature (solid lines) after laser pulse absorption. The critical temperature Tc when water becomes hydro-dynamically unstable is indicated at $647 \mathrm{~K}$.

The dependence of the pulse energy on the number of pulses for standardized fluorescence levels ("fluorescence brightness") is shown in Figure 6. A given fluorescence level corresponds to a specific amount of fluorescence molecules in the cells per well. We analyzed the number of laser pulses and pulse energy to yield four different fluorescence levels.

With an increasing number of pulses, less pulse energy is needed for an efficient permeabilization. An average accumulation strength of $\mathrm{k}=5.57 \pm 0.02$ was evaluated

Table 1 Near field and temperature related values for AuNP irradiated with $796 \mathrm{~nm}$ and $6.26 \mathrm{~W} / \mathrm{cm}^{2}$

\begin{tabular}{llllll}
\hline & $\mathbf{3 0} \mathbf{~ n m}$ & $\mathbf{8 0} \mathbf{~ n m}$ & $\mathbf{1 5 0} \mathbf{~ n m}$ & $\mathbf{2 0 0} \mathbf{~ n m}$ & $\mathbf{2 5 0} \mathbf{~ n m}$ \\
\hline Near field volume $\left[\mathrm{nm}^{3}\right]\left(\mathrm{I}_{\text {max }} / \mathrm{e}^{2}\right)$ & $7 \times 10^{3}$ & $1.2 \times 10^{5}$ & $7.1 \times 10^{5}$ & $1.6 \times 10^{6}$ & $2.8 \times 10^{6}$ \\
Average near field intensity $\left[\mathrm{W} / \mathrm{cm}^{2}\right]$ & $3.8 \times 10^{12}$ & $2.5 \times 10^{12}$ & $1.7 \times 10^{12}$ & $2.5 \times 10^{12}$ & $3.3 \times 10^{12}$ \\
Absorption efficiency $Q_{\text {abs }}$ & 0.025 & 0.05 & 0.145 & 0.125 & 0.08 \\
Particle temperature $[\mathrm{K}]$ & 541 & 561 & 726 & 578 & 471 \\
\hline
\end{tabular}




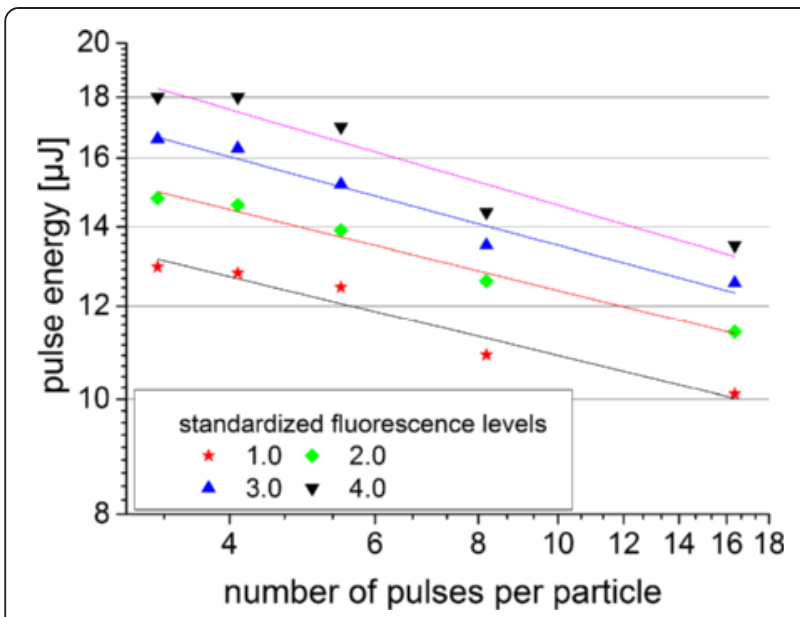

Figure 6 Influence of the pulse energy on the number of pulses for standardized fluorescence levels. Every data point represents the mean value ( $n=15$ measurements).

by a power-law fit (Table 2). This indicates that 5 photons with a photon energy of $1.55 \mathrm{eV}$ at the applied wavelength of $796 \mathrm{~nm}$ are absorbed simultaneously to reach the ionization threshold of $6.6 \mathrm{eV}$ for water [26].

When laser radiation is absorbed by the electrons of the AuNP the energy is transferred from the electrons to the particle lattice due to electron phonon coupling within a time span of a few ps and the particle temperature increases $[29,30]$. The temperature of the electrons and the lattice can be calculated with a two-temperature model (Figure 5D) [31]. The lattice temperature reaches the highest temperature of $726 \mathrm{~K}$ for $150 \mathrm{~nm}$ particles. This temperature is above the critical temperature $\left(\mathrm{T}_{\mathrm{c}}\right)$ for phase transformation in water. For all other particles sizes this critical temperature is not reached. This reflects the different values for absorption efficiencies $Q_{\text {abs }}$ listed in Table 1.

The influence of the laser irradiation and possible changes in the particle morphology due to melting or fragmentation were analyzed by absorbance spectra of irradiated and non-irradiated particles (Figure 7A). After irradiation of $250 \mathrm{~nm}$ particles with radiant exposures of $60 \mathrm{~mJ} / \mathrm{cm}^{2}$ and $100 \mathrm{~mJ} / \mathrm{cm}^{2}$ a blue shift of the peak of $0.5 \mathrm{~nm}$ and $1.75 \mathrm{~nm}$, occurred respectively (Table 3)). These shifts were in the SEM range of the untreated control. A reason for small changes can be polishing

Table 2 Power-law fit

\begin{tabular}{llll}
\hline & Threshold energy $\mathrm{E}_{\mathbf{1}}[\boldsymbol{\mu} \mathbf{J}]$ & $\boldsymbol{k}$ & $\mathbf{R}^{\mathbf{2}}$ \\
\hline 1.0 & $16.06 \pm 0.7$ & $5.88 \pm 0.02$ & 0.93 \\
2.0 & $18.36 \pm 0.7$ & $5.88 \pm 0.01$ & 0.98 \\
3.0 & $20.79 \pm 0.7$ & $5.55 \pm 0.02$ & 0.94 \\
4.0 & $23.27 \pm 0.7$ & $5.00 \pm 0.03$ & 0.90 \\
\hline
\end{tabular}

Dependence of the pulse energy on the number of pulses for standardized permeabilization efficiencies. effects due to surface melting of the particle, which occurs below the melting point of bulk gold [17]. At radiant exposures of $140 \mathrm{~mJ} / \mathrm{cm}^{2}$ and higher values the spectrum were broadly blue shifted (Table 3 ) and a narrowing of the spectrum occurred (Figure 7A). The spectrum of a $250 \mathrm{~nm}$ particle exposed to a radiant exposure of $300 \mathrm{~mJ} / \mathrm{cm}^{2}$ is broadly similar to the spectrum of $80 \mathrm{~nm}$ particles [32]. This clearly indicates a change in particle size due to laser exposure which can be induced by particle evaporation or near field ablation [17].

The value of the peak shift for different particle sizes after laser radiation in dependence of the radiant exposure is shown in Figure 7B. The highest peak shift of 80 $\mathrm{nm}$ was measured for $150 \mathrm{~nm}$ particles and barley changes with increasing radiant exposures. Relating to the AuNP size of $250 \mathrm{~nm}$ used for transfection a peak shift occurred at radiant exposures $\geq 140 \mathrm{~mJ} / \mathrm{cm}^{2}$. Furthermore, the amount of the peak shift for all radiant exposures is lower than for $150 \mathrm{~nm}$ particles which correlate with the calculated temperatures and near field enhancement in Figure 5.

\section{Discussion}

In our study, we characterized the underlying mechanism and the potential of nanoparticle mediated cell membrane perforation in combination with fs-laser pulses as an alternative optical transfection method. Therefore the influencing parameters on the achieved perforation rate and cell viability were systematically determined and the successful transfection of cells with a fluorescent siRNA as well as the knock down of the oncogene HMGA2 in tumor cells with specific siRNAs was demonstrated. Furthermore, the passive binding of AuNP to the cell membrane was studied.

Multiphoton and scanning electron microscopy images show the localization of AuNP near the cell membrane. Depending on the incubation time of the AuNP, single particles or clusters are located near, or associated with, the membrane. After an incubation time of $3 \mathrm{~h}$ the AuNP are clearly visible near the cell membrane. Within this time the particles form clusters with enhanced scattering of the laser light proved by multiphoton microscopy [33]. The agglomeration of particles after 3 hours is also visible in the ESEM images. This is in agreement with findings from Chithrani et al. who determined the uptake half-life at $2.24 \mathrm{~h}$ for $74 \mathrm{~nm}$ AuNP [33]. Furthermore, they evaluated the uptake of the number of particles per cell and also showed that the number of particles per cell saturated after $5 \mathrm{~h}$. In the present study a particle number of approx. 160 was estimated at the membrane of a single cell for an incubation concentration of $11 \mu \mathrm{g} / \mathrm{ml}$. Baumgart et al. [22] counted per cell $90 \pm 23$ AuNP with a diameter of $100 \mathrm{~nm}$ at an incubation concentration of $8 \mu \mathrm{g} / \mathrm{ml}$ after an incubation time 

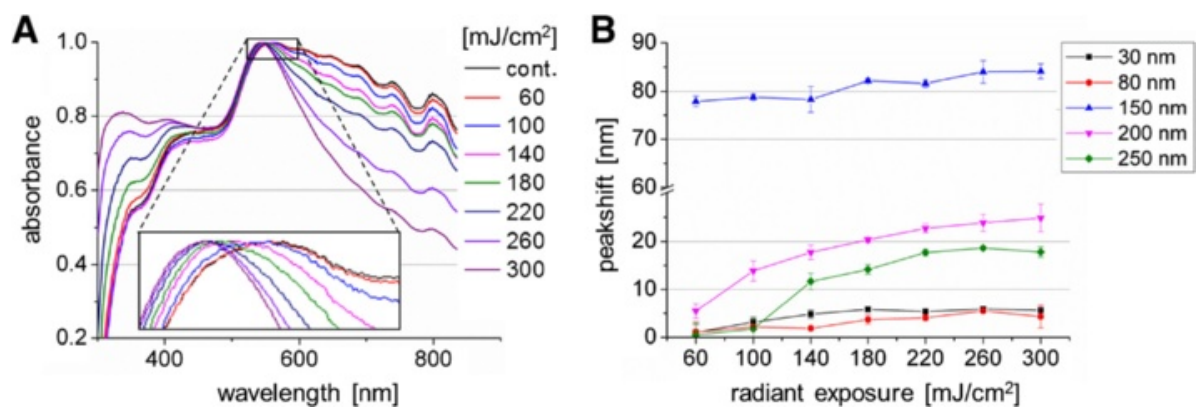

Figure 7 Influence of different laser radiations on AuNP. A) Absorbance spectrum of $250 \mathrm{~nm}$ particles after laser exposure. B) Mean value of the peak shift \pm SEM in the absorbance spectrum after laser exposure for different AuNP sizes ( $n=4$ experiments).

of $6 \mathrm{~h}$ using SEM images. Taking into account that in this work a higher particle concentration and a larger diameter was used (and therefore a faster sedimentation of the particles takes place) the results are in a very good agreement.

In addition, Chithrani et al. evaluated the number of AuNP per vesicle and found an average number of 3 AuNP per vesicle for $100 \mathrm{~nm}$ particles. In comparison to our SEM images (see Figure 2B) we assume that one 200 $\mathrm{nm}$ particle per vesicle get endocytosed by the cell. As bare AuNP are used, a serum protein corona is formed at the particles surface and no specific binding at the cell membrane is likely to occur. Therefore, we suggested the receptor-mediated endocytosis (RME) to be the acting uptake mechanism [34].

The initial mechanism of plasmon mediated cell membrane permeabilization is still a current matter in research. Depending on the parameters, different mechanisms and effects are assumed. These are thermal ("nanoheater effect") [19,35], or near field enhancement effects ("nanolens effect") $[18,35]$. In addition, the generation of a low density plasma induced by multiphoton ionization combined with thermal effects can possibly lead to membrane permeabilization $[14,15]$. For short laser pulses in the nanosecond-picosecond regime, where the energy is mainly absorbed by the particle, thermal effects could be the main mechanism for membrane permeabilization [36-38]. After AuNP heating, the water evaporates followed by a shockwave and forming a cavitation bubble around the exposed particles as reported by Pitsillides et al. and Zharov et al. and enabling membrane perforation $[39,40]$. Using fs laser pulses, nanocavitation bubbles can be formed by the induced field enhancement. This enhancement can lead to an optical breakdown near the particle and to the generation of a shockwave $[18,36]$. In this work, the evaluated intensities at the surface of single AuNP are near the threshold for an optical breakdown in the low density plasma regime. In existing studies, different concentrations of AuNP were required to achieve cell membrane perforation [15]. Higher numbers of particles are necessary to manipulate the cells with fs laser pulses [22,41]. Due to the formation of AuNP clusters the near field is further enhanced in comparison to single particles. The neighboring particles interact via the scattered waves and due to plasmon coupling "hot spots" are formed $[42,43]$. Taking into account that the field enhancement is higher for AuNP clusters compared to single particles, the intensities could be above the optical breakdown threshold [42].

Our assumption herein, that clusters of AuNP at the cell membrane are necessary to induce a field enhancement by fs laser pulses which is high enough to perforate the cell membrane. This is supported by the presented microscopic images and the number of AuNP utilized in this and other studies using fs laser pulses for membrane perforation [22,41]. Within the performed experiments we showed the efficient and transient permeabilization of the cell membrane due to an expected enhancement of the near field at the AuNP clusters. Based on this and the evaluated simultaneous absorption of 5 photons in the pulse number dependent experiments (Figure 6) we understand the near field enhancement followed by the multiphoton ionization of the surrounding medium as the initial perforation mechanism.

The fs laser pulses are enhanced in the near-field of the particle for membrane permeabilization by surface plasmon resonances. NIR fs laser pulses benefit from a

Table 3 Mean values \pm SEM for the peak shift in the absorbance spectrum

\begin{tabular}{lllllllll}
\hline Radiant exposure $\left[\mathbf{m J} / \mathrm{cm}^{2}\right]$ & $\mathbf{0}$ & $\mathbf{6 0}$ & $\mathbf{1 0 0}$ & $\mathbf{1 4 0}$ & $\mathbf{1 8 0}$ & $\mathbf{2 2 0}$ & $\mathbf{2 6 0}$ & $\mathbf{3 0 0}$ \\
\hline Shift $[\mathrm{nm}]$ & 0 & 0.5 & 1.75 & 11.68 & 14.18 & 17.68 & 18.62 & 17.81 \\
SEM $[\mathrm{nm}]$ & \pm 2.98 & \pm 2.68 & \pm 2.21 & \pm 1.71 & \pm 1.01 & \pm 0.66 & \pm 0.13 & \pm 1.06 \\
\hline
\end{tabular}

Irradiation of $250 \mathrm{~nm}$ particles with different radiant exposures ( $\mathrm{n}=4$ experiments). 
low thermal impact and a high penetration depth into tissue which is important for in vivo experiments. Furthermore, laser irradiation mediated fragmentation of nanoparticles is especially for in vivo settings an important issue. Fragmentation in small nanoparticles under 5 $\mathrm{nm}$ can lead to toxicity by intercalation into the DNA [44]. The comparison of fs pulses and ns pulses reveal a more pronounced change in particle morphology for longer $(850 \mathrm{ps}, 532 \mathrm{~nm})$ pulses. In absorbance measurements, no pronounced peak shift (as indicator for particle morphology and size change) was detected for a fluence of $100 \mathrm{~mJ} / \mathrm{cm} 2$, which exceeds the optimal fluence for cell manipulation $(80 \mathrm{~mJ} / \mathrm{cm} 2)$ using NIR fs pulses (Table 3). In comparison to this, for 850 ps ( $\approx 1 \mathrm{~ns}$ ) pulses a peak shift of $15.4 \mathrm{~nm}$ was determined using the optimal manipulation fluence of $20 \mathrm{~mJ} / \mathrm{cm} 2$. The change in particle morphology was caused due to thermal effects and the strong linear absorption at 532 $\mathrm{nm}$. Nevertheless, the cell viability stayed above $80 \%$ in all the performed experiments suggesting the use of visible ns pulses for in vitro experiments [15]. For fs pulses, the cell viability was determined to be above $90 \%$. The presented results and the advantages of NIR fs laser pulses (e.g. a high penetration depth and the avoidance of photo thermal effects) indicate the great potential of fs laser for in vivo manipulation. Furthermore the development of endoscopic systems for ultrafast laser microsurgery [45] or fiber based approaches [46] makes the application of ultrashort laser pulses potentially suitable for fs laser in vivo cell manipulation. Additionally, first in vivo experiments showed the generation of nanobubbles around AuNP clusters for selective cancer cell killing using short, $780 \mathrm{~nm}$ laser pulses [47]. Next to the properties of the fs laser pulses, an advantage of the presented method is the double selectivity by the spatial confined radiation (Figure 8A) and the possibility of specific cell targeting by antibody conjugated AuNPs. The latter can be used to induce selective cell manipulation or ablation in both, in vitro and in vivo models. For example, the treatment of squamous carcinoma cells in the buccal mucosa or at the tongue. Further in tumor scenarios where minimal invasive tissue ablation is essential as malignant glioblastoma, it is crucial to sustain nontarget (healthy) tissue. Here the presented method can be a powerful tool. Exemplarily for primary cell manipulation a membrane impermeable fluorescent dye was delivered into a human embryonic stem cell (ES) cell line hES3 and a human induced pluripotent stem cell (iPSC) line hCBiPS2 (Figure 8B)." The results of the siRNA experiments show that fs nanoparticle mediated laser transfection is suitable for high throughput functional gene assays due to the short processing time of approximately 10 min per 96 well plate. As the applied AuNP were shown to be non-toxic, this method is excellent

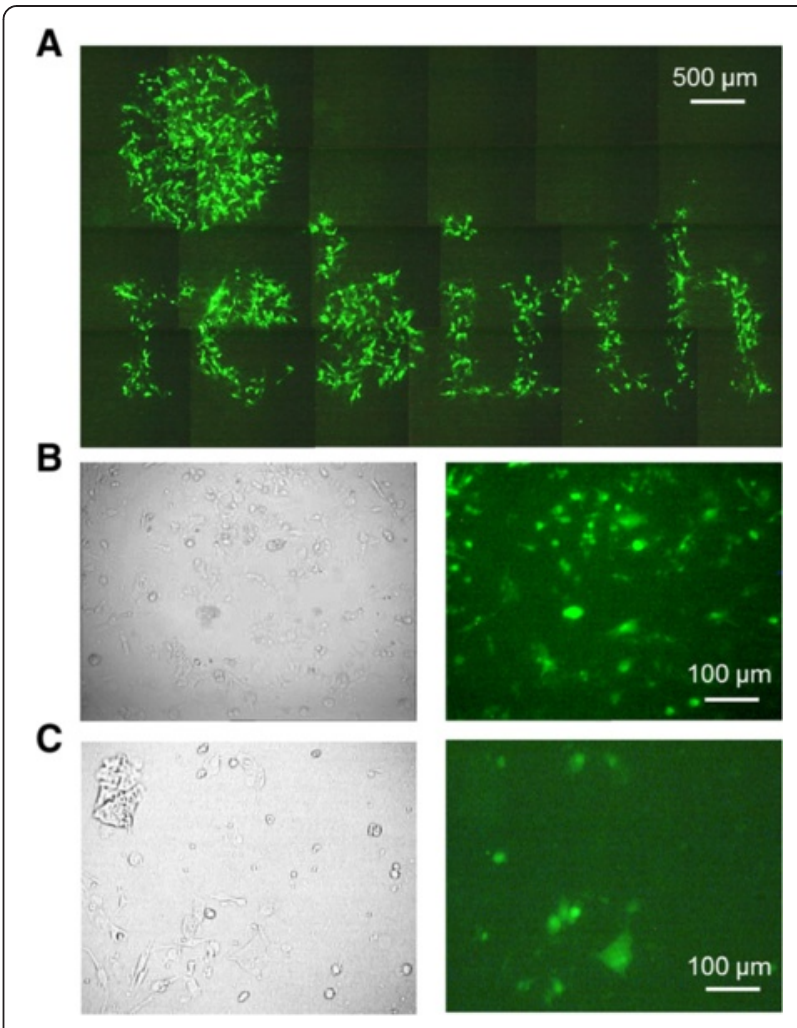

Figure 8 Spatial selective and pluripotent cell line manipulation. A) Selective cell manipulation of ZMTH3 cells by spatial confined radiation using a shadow mask. The image consists of 24 single fluorescence images and shows the word "rebirth" B-C) Manipulation of a human ES cell line hES3 (B) and the human IPSC line hCBiPS2 (C): A membrane impermeable dye (Lucifer yellow) was delivered into the pluripotent cells. Bright field image (left) and fluorescence image (right).

suited for in vitro application but also for other applications in molecular medicine. Furthermore, it can be applied for the manipulation of various cell types as shown in our previous work and by Baumgart et al. [16,22]. Additional applications as gene or cell therapeutic approaches can be served by this technique. As an example, it is possible to manipulate high cell numbers required for e.g. tumor vaccination strategies in an appropriate time. The knock down of the oncogene HMGA2 in canine prostate carcinoma cells was carried out successfully as shown by real time PCR expression analyses (Figure 4G). Due to the extraordinary high HMGA2 expression in the CT1258 cell line a incomplete siRNA mediated HMGA2 knock down within the treated cells was to be expected. Conventional HMBA2 knock down in less aggressive human pancreatic cell lines by Watanabe et al. [48] resulted in higher efficiencies. However, we opted to target the canine prostate cancer derived cell line CT1258 as canine prostate cancer represents the only spontaneously arising model for human prostate cancer with considerable incidence. This includes several tumor relevant aspects as biological 
behavior, marker gene expression and histological presentation [49]. Thus, a successful establishment of a therapeutic approach in dogs will offers high transfer potential to a human clinical setting. Consequently, prior to human clinical trials, a valid clinical trial in dogs as naturally occurring model is of major interest allowing to monitor the therapeutic intervention in an genetic outbreed model with unmanipulated immune system.

\section{Conclusion}

Our studies on nanoparticle mediated fs laser cell perforation show, that this method is suitable for high throughput siRNA transfection with high efficiency and low cell toxicity. To establish this method as an alternative transfection technique, the manipulation of different cell types will be continued in further studies. However, due to the underlying physical mechanism the permeabilization should be cell type independent. Based on the mechanistic investigations, we assume that an enhancement of the near field occurs at AuNP clusters. This leads to the generation of a low density plasma with multiphoton ionization of the surrounding liquid, which in turn perforates the cell membrane. The uptake mechanism of extracellular molecules remains to be investigated in further experiments [50]. The presented method is an alternative transfection method to deliver molecules into living cells being particularly well suited for standardized processes like high throughput or high content screening assays for fundamental and pharmaceutical research.

\section{Methods}

\section{Cell culture}

The canine pleomorphic mammary adenoma cell line ZMTH3 [51] was cultured routinely in RPMI 1640 supplemented with $10 \%$ fetal calf serum (FCS) and 1\% penicillin/ streptomycin (Biochrom AG, Berlin, Germany). Rat granulosa cells (GFSHR-17) were cultivated in DMEM (Dulbecco's Modified Eagle Medium) supplemented with $5 \%$ FCS, 1\% penicillin/streptomycin (Biochrom AG, Berlin, Germany). The canine prostate adenocarcinoma cell line CT1258 was derived from an extremely aggressive canine prostate carcinoma [52] and cultured in Medium 199 (Life Technologies GmbH, Darmstadt, Germany) supplemented with $10 \%$ FCS and $2 \%$ penicillin/streptomycin (Biochrom AG, Berlin, Germany). The human ES cell line hES3 and the human iPSC line hCBiPS2 [53] were cultured and expanded on irradiated mouse embryonic fibroblasts (MEF) in knockout DMEM supplemented with 20\% knockout serum replacement, $1 \mathrm{mM}$ L-glutamine, $0.1 \mathrm{mM}$ $\beta$-mercaptoethanol, $1 \%$ nonessential amino acid stock (all from Life Technologies) and 10ng/ml bFGF (supplied by the Institute for Technical Chemistry, Leibniz University Hannover). One day before laser transfection cells were detached from the feeder layer by $0.2 \%$ collagenase IV (Life Technologies) followed by an incubation step with TrypLE (Life Technologies) for single-cell dissociation and plated onto Matrigel ${ }^{\mathrm{Tm}}$ (BD Biosciences) coated dishes in MEF-conditioned medium.

\section{Laser setup}

The used automated setup for cell manipulation is operating with a fs amplifier laser system (Spitfire Pro, Newport Corporation, Irvine, USA). The generated laser pulses have a pulse duration of $120 \mathrm{fs}$ at a fixed wavelength of $796 \mathrm{~nm}$. The output power of the system is $2.1 \mathrm{~W}$ at a repetition rate of $5 \mathrm{kHz}$. To irradiate the biological tissue, the laser pulses were guided through an automatized attenuator consisting of a $\lambda / 2$-plate and a polarizing beam splitter and reflected by two scanning mirrors (Litrack, JMLaser, Müller Elektronik, Spaiching, Germany). A convex lens with a focal length of $800 \mathrm{~mm}$ was used to focus the laser pulses onto the sample, located on the automatized stage (OptiScan, Prior, Jena, Germany), resulting in a spot diameter of $164 \mu \mathrm{m}$.

\section{Nanoparticle incubation}

Prior to the laser cell manipulation experiments and to investigate the interaction of AuNP with the cell membrane, the cells were co-incubated with the AuNP at $37^{\circ} \mathrm{C}$ in a $5 \% \mathrm{CO}_{2}$ atmosphere. The AuNP were chemically manufactured in presence of chloroauric acid (PGO, Kisker Biotech, Steinfurt, Germany). Uncoated AuNP of $80 \mathrm{~nm}$, $150 \mathrm{~nm}, 200 \mathrm{~nm}, 250 \mathrm{~nm}$ were used.

\section{Multiphoton microscopy}

Images were obtained to evaluate the incubation time for AuNP mediated cell permeabilization and the possibility of a passive binding of the particles. Briefly, granulosa cells were incubated with $150 \mathrm{~nm}$ gold particles and imaged after different incubation times. After a PBS wash, the cells were observed with a custom built multiphoton microscope which is based on a fs-laser system tunable from $\lambda=690$ $\mathrm{nm}$ to $1040 \mathrm{~nm}$ (Chameleon ultra II, Coherent, Göttingen, Germany) [27]. The images were recorded through a 100x oil immersion objective (Carl Zeiss AG, "Plan-Neofluar", $\mathrm{NA}=1.3$ ) at an excitation wavelength of $\lambda_{\mathrm{exc}}=700 \mathrm{~nm}$.

\section{Scanning electron microscopy (SEM) and environmental scanning electron microscopy (ESEM)}

To investigate the interaction of cells and AuNP images of ZMTH3 cells were generated after different times of co-incubation with $200 \mathrm{~nm}$ particles. The cells were washed after co-incubation with AuNP and fixed by adding a $4 \%$ paraformaldehyde (PFA) solution with $0.2 \%$ glutaraldehyde at $4^{\circ} \mathrm{C}$. For ESEM imaging the cells were washed after 20 min with distilled water. For SEM, the cells were further treated at room temperature for 20 
min with a $2 \%$ osmium tetroxide solution. Subsequently, the cells were washed 3 times with water for 5 min before incubation with different ethanol concentrations for 10 min each $(30 \%, 50 \%, 70 \%, 90 \%, 95 \%, 95 \%$ and $3 \times$ $100 \%)$. Before sputtering the cells with a $5 \mathrm{~nm}$ gold layer, the cells were dried for 30 min under laminar air flow conditions. For counting AuNP at the cell membrane after incubation, ImageJ was used [54]. Values represent the mean of $n=6$ images \pm SEM.

\section{Plate reader measurements}

To evaluate the optimal parameters of an efficient and gentle transfection, $2.5 \times 10^{4}$ canine ZMTH3 cells per well were seeded in a black wall/clear bottom 96 well plate (BD Bioscience, Heidelberg, Germany) $24 \mathrm{~h}$ before laser treatment. As an indicator of membrane permeabilization, fresh medium with $2 \mathrm{mg} / \mathrm{ml}$ of $10 \mathrm{kDa}$ FITC-dextran (Sigma-Aldrich, Steinheim, Germany) was added to the cells. After laser treatment, the cells were incubated for 30 min followed by several washing steps until the background fluorescence from the permeabilization indicator (10 kDa FITC dextran) was eliminated. To measure the metabolic activity of the cells, $10 \%(\mathrm{v} / \mathrm{v})$ of the resazurin based, fluorometric QBlue viability assay kit (BioCat $\mathrm{GmbH}$, Heidelberg, Germany) was added to the medium. During an incubation time of $1 \mathrm{~h}$, viable cells converted resazurin into the fluorescent form resuorufin. The fluorescence levels of the delivered FITC dextran (EX488/ EM520 nm) for molecular delivery and the resorufin (EX570/EM600 nm) as an indicator for viability were measured by the Infinite 200 Pro plate reader (Tecan, Männedorf, Switzerland). The value for FITC dextran delivery was calculated by subtracting the fluorescent background from each sample and afterwards the highest FITC fluorescence level was normalized to 1 . The cell viability $(\mathrm{V})$ was determined by the QBlue fluorescence level of the sample $\left(\mathrm{F}_{\mathrm{s}}\right)$, the fluorescence of the untreated control $\left(\mathrm{F}_{\mathrm{C}}\right)$ and the background $\left(\mathrm{F}_{\mathrm{B}}\right)$ (Equation $\left.(2)\right)$.

$$
V=\frac{F_{S}-F_{B}}{F_{C}-F_{B}} \cdot 100
$$

The efficiency ratio (E) was calculated by correlating the fluorescence level for molecular delivery $\left(\mathrm{F}_{\mathrm{FITC}}\right)$ and viability (V) using equation (3). Afterwards the values were normalized to 1 .

$$
E=F_{F I T C} \cdot V
$$

\section{Simulation of the particle temperature and near field}

For a deeper insight into the mechanisms involved in membrane permeabilization using fs laser pulses, the particle temperature and the near field were analyzed. The temperature of the AuNP during fs irradiation was calculated based on a two temperature model, employing data for the specific heat capacity of the electrons and the electron phonon coupling constant from Lin et al. [55]. Temperature loss due to interaction with the surrounding medium was not considered due to the short timescales used. The field strength and intensity as well as the near field volume were simulated by the discrete dipole approximation, using the software DDSCAT [56,57]. A dipole separation of less than $3.5 \mathrm{~nm}$ was used for the largest sphere with a diameter of $250 \mathrm{~nm}$. Modeling of the optical breakdown intensities in the near field was performed according to the Keldysh theory following the approach used by Vogel et al. [26,58]. The maximum intensity divided by the square of e was considered as near field volume and the enhancement in the modeling of the optical breakdown as well as the near field volume were averaged in the according area.

\section{UV-Vis spectroscopy}

Particle spectra were monitored to evaluate a possible peakshift (as an indicator for a change in particle size/ shape) of laser irradiated particles compare to untreated particles. Therefore an UV/Vis spectroscope (UV 1650PC, Shimadzu, Duisburg, Germany) was used. The particles were diluted in culture media (RPMI as described before) without phenol red at a concentration of $50 \mu \mathrm{g} / \mathrm{ml}$. Using a 96 well plate, the samples with a total volume of $200 \mu \mathrm{l}$ per well were irradiated in a meander pattern.

\section{Fluorescence microscopy}

In order to evaluate the transfection efficiency of the CT1258 cells, fluorescence microscopy was applied. $24 \mathrm{~h}$ before laser treatment, $1 \times 10^{4}$ cells were seeded in each well of a 24 well plate (PAA Laboratories, Cölbe, Germany). For siRNA transfection, $10 \mu \mathrm{M}$ of a fluorescently labeled (AlexaFluor488) siRNA (Qiagen, Hilden, Germany) was added to the extracellular medium before laser treatment. The samples were treated with the optimized parameters as evaluated within the plate reader measurements. After laser treatment, the cells were incubated for $30 \mathrm{~min}$ followed by several washing steps until the background fluorescence from the fluorescent siRNA was eliminated. Three independent experiments in duplicates were performed on different days. Three images of each well were analyzed using Image J. By counting the cell nuclei (ca. 546 per image, stained with HOECHST33342) and transfected cells (Alexafluor488 siRNA positive cells) the transfection efficiency was determined. Propidium Iodide was used as an indicator for necrotic cells.

\section{Flow cytometry analysis}

Flow cytometric analysis was performed to evaluate the transfection efficiencies and the necrotic- and apoptotic rate. $24 \mathrm{~h}$ before laser treatment, $1.5 \times 10^{5}$ cells were 
seeded in each well of a 24 well plate. For siRNA transfection, $10 \mu \mathrm{M}$ of a fluorescently labeled (AlexaFluor488) siRNA was added to the extracellular medium before laser treatment. The samples were treated with optimized parameters as evaluated within the plate reader measurements. Three hours after laser treatment the samples were prepared for flow cytometric analysis. Therefore, the cells were washed and trypsinized (TrypLE ${ }^{\mathrm{m}}$, Life Technologies (LT), Darmstadt, Germany). A viability staining with Annexin V (V-PE-Cy5 Apoptosis Detection Kit, BioCat, Heidelberg, Germany) to detect the apoptotic cells, and with $1.5 \mu \mathrm{M}$ Propidium Iodide (Invitrogen, Darmstadt, Germany) to identify necrotic cells, was performed. The positivity of siRNA transfected cells was determined by comparing the AlexaFluor488 fluorescence intensity to native cells, both measured in the FL1-H channel using a FACSCalibur flow cytometer (BD Bioscience, Heidelberg, Germany). Within the native cell population, a gate was set determining $98 \%$ of the native cells as non-transfected using the software Cell Quest (BD Bioscience, Heidelberg, Germany). This gate was subsequently applied on the siRNA transfected cell population resulting in the percentage of positive and non-transfected cells. To determine the ratio of apoptotic and necrotic cells within the siRNA transfected samples, the Annexin V and PI labelled cells were analyzed for PE-Cy5 fluorescence in the FL4-H channel and for PI in the FL2-H channel. Within the native cells a gate was set at which a cell population of $2 \%$ was identified as Annexin and PI positive and transferred to the sample with siRNA transfected cells to discriminate living from apoptotic and necrotic cells. For statistical analyses, the student's t-test was used. The significance is given as * for $\mathrm{p}<0.05$, ** for $\mathrm{p}<0.01$ and ${ }^{* * * *}$ for $\mathrm{p}<0.001$.

\section{HMGA2 suppression analysis}

As a proof of principle, that the presented method is suitable for molecular medicine approaches a functional gene knock down experiment was performed. We used the tumor cell line CT1258 which is characterized by overexpression of endogenous HMGA2 [25]. 24 h prior to transfection $3 \times 10^{5}$ cells were seeded per well into a 6 well plate (Greiner Bio-One GmbH, Frickenhausen, Germany). Cells were laser-transfected with $10 \mathrm{nM}$ of different antiHMGA2 siRNAs, a scrambled siRNA and a siRNA mix consisting of $10 \mathrm{nM}$ of each of the four anti-HMGA2 siRNAs (Riboxx, Radebeul, Germany). The corresponding siRNA sequences are listed in Table 4. After a time span of $48 \mathrm{~h}$ the growth medium was removed from the CT1258 cells and $1 \mathrm{ml}$ Tryp LE Express (Life Technologies $\mathrm{GmbH}$, Darmstedt, Germany) was applied on cells. Once the cells were detached $1 \mathrm{ml}$ cultivation medium was added to stop the reaction. Cell suspension was pelleted at $300 \times \mathrm{g}$ for $5 \mathrm{~min}$. The supernatant was discarded and the pellet stored at $-80^{\circ} \mathrm{C}$ until further processing.
Table 4 Name and sequence of the used siRNAs for HMGA2 knock down

\begin{tabular}{ll}
\hline siRNA name & sequence \\
\hline A2-3UTR 1 & 5'-UUAAUUCUCUCCGUAGCUCCCCC-3' \\
A2-3UTR 2 & 5'-UCUUACUGUUCCAUUGGCCCCC-3' \\
A2-3UTR 3 & 5'-AUUAUCCUUAAGAACCUAGCCCCC-3' \\
A2-3UTR 4 & 5'-UUCUUACUGUUCCAUUGGCCCCC-3' \\
scrambled siRNA & 5'-UAAGCACGAAGCUCAGAGUCCCCC-3' \\
\hline
\end{tabular}

\section{RNA extraction}

For PCR analysis total RNA was isolated according to the "NucleoSpin miRNA" protocol (Macherey \& Nagel, Düren, Germany). Small and large RNAs were finally eluted in $30 \mu \mathrm{l}$ nuclease free water. Total RNA concentration was measured with the Synergy 2 reader (BioTek Instruments $\mathrm{GmbH}$, Bad Friedrichshall, Germany).

\section{Quantitative one step real-time PCR analysis}

For the relative HMGA2 / ACTB quantification $25 \mathrm{ng}$ total RNA were mixed with SYBR Green, HMGA2 or $A C T B$ specific primers, nuclease free water (Qiagen, Hilden, Germany) and reverse transcriptase according to the "QuantiTect SYBR Green RT-PCR" protocol (Qiagen, Hilden, Germany). The fluorescence of each sample was analyzed in triplicates. As negative controls a nontemplate and a no-reverse transcriptase control were included. The experiments were performed using the Mastercycler ep realplex (Eppendorf AG, Hamburg, Germany). qRT-PCR conditions were as follows: $30 \mathrm{~min}$ at $50^{\circ} \mathrm{C}$ and $15 \mathrm{~s}$ at $95^{\circ} \mathrm{C}$, followed by 40 cycles with $15 \mathrm{~s}$ at $94^{\circ} \mathrm{C}, 30 \mathrm{~s}$ at $60^{\circ} \mathrm{C}$ and $30 \mathrm{~s}$ at $72^{\circ} \mathrm{C}$. Finally a melting curve analysis was performed to verify specificity and identity of the qRT-PCR products according to the Eppendorf Mastercycler ep realplex instrument instructions. For the comparison of the relative gene expression levels based on the $\Delta \Delta C T$ method the gene expression level of the untreated CT1258 cells was used as calibrator (calibrator expression level was set as 1). Statistical analysis of the qRT-PCR results was done by using the software tool REST 2009, version 2.0.13. A p-value of $\leq 0.05$ was considered as statistically significant.

\section{Competing interests}

The authors declare that they have no competing interests.

\section{Authors' contributions}

MS: Conceived and designed the experiments, performed the laser perforation and transfection experiments. Performed multi photon imaging and laser-particle interaction experiments, manuscript drafting and wrote the paper. $\mathrm{DH}$ : Conceived and designed the experiments, performance of the SEM imaging experiments, participated in the perforation experiments. SK: Carried out the simulation for the particle temperature and near field enhancement. Wrote parts of the paper. SWi: Performed flow cytometry analysis and analyzed the data, Participated in drafting the transfection experiments, wrote parts of the paper. SWa: Performance of PCR analysis and data processing IN: Contributed reagents/materials/analysis tools and participation at biological study design. TR: Manuscript drafting, Contributed reagents/materials/analysis tools. HME: Donated cell line, partial study design. HM: 
Drafting and wrote parts of the manuscript. $\mathrm{AH}$ : Conceptional design of the study, reagents/materials/analysis tools, manuscript drafting and finalization. All authors read and approved the final manuscript.

\section{Acknowledgments}

The authors thank Regina Carlson for technical support in flow cytometry and the German Research Foundation DFG (within the Transregio 37 and the excellence cluster REBIRTH) for the financial support. We thank Ulrich Martin (Leibnitz Research Laboratories for Biotechnology and Artificial Organs (LEBAO), Hannover Medical School) for providing the hES3 and hCBiPS2 cells.

\section{Author details}

'Department of Biomedical Optics, Laser Zentrum Hannover, Hollerithallee 8, 30419 Hannover, Germany. ${ }^{2}$ Small Animal Clinic, University of Veterinary Medicine Hannover, Bünteweg 9, 30559 Hannover, Germany. 'Department of Hematology, Oncology, and Palliative Medicine, University of Rostock, Ernst- Heydemann-Str. 6, 18057 Rostock, Germany. ${ }^{4}$ Department of Cardiothoracic Transplantation and Vascular Surgery, Hannover Medical School, Carl-Neuberg-Str. 1, 30625 Hannover, Germany. ${ }^{5}$ nstitut für Quantenoptik Leibniz Universität Hannover Welfengarten 1, 30167 Hannover, Germany.

Received: 10 September 2014 Accepted: 1 December 2014 Published online: 03 February 2015

\section{References}

1. Roth JA, Cristiano RJ: Gene therapy for cancer: what have we done and where are we going? J Natl Cancer Inst 1997, 89:21-39.

2. Selkirk S: Gene therapy in clinical medicine. Postgrad Med J 2004, 80:560-570.

3. Dorsett $Y$, Tuschl T: siRNAs: applications in functional genomics and potential as therapeutics. Nat Rev Drug Discov 2004, 3:318-329.

4. Hacein-Bey-Abina S, Von Kalle C, Schmidt M, McCormack MP, Wulffraat N, Leboulch P, Lim A, Osborne CS, Pawliuk R, Morillon E, Sorensen R, Forster A, Fraser P, Cohen Jl, de Saint Basile G, Alexander I, Wintergerst U, Frebourg T, Aurias A, Stoppa-Lyonnet D, Romana S, Radford-Weiss I, Gross F, Valensi F, Delabesse E, Macintyre E, Sigaux F, Soulier J, Leiva LE, Wissler M, et al: LMO2-associated clonal T cell proliferation in two patients after gene therapy for SCID-X1. Science 2003, 302:415-419.

5. Uchida E, Mizuguchi H, Ishii-Watabe A, Hayakawa T: Comparison of the efficiency and safety of non-viral vector-mediated gene transfer into a wide range of human cells. Biol Pharm Bull 2002, 25:891-897.

6. Karra D, Dahm R: Transfection techniques for neuronal cells. J Neurosci 2010, 30:6171-6177

7. Papapetrou EP, Zoumbos NC, Athanassiadou A: Genetic modification of hematopoietic stem cells with nonviral systems: past progress and future prospects. Gene Ther 2005, 12(Suppl 1):118-130.

8. Krausz E: High-content siRNA screening. Mol BioSyst 2007, 3:232-240.

9. Tsukakoshi M, Kurata S, Nomiya Y, Ikawa Y, Kasuya T: A novel method of DNA transfection by laser microbeam cell surgery. App Phys B 1984, 35:135-140

10. Terakawa M, Ogura M, Sato S, Wakisaka H, Ashida H, Uenoyama M, Masaki Y, Obara M: Gene transfer into mammalian cells by use of a nanosecond pulsed laser-induced stress wave. Opt Lett 2004, 29:1227-1229.

11. Tirlapur UK, König K: Targeted transfection by femtosecond laser. Nature 2002, 418:290-291.

12. Soughayer JS, Krasieva T, Jacobson SC, Ramsey JM, Tromberg BJ, Allbritton NL: Characterization of cellular optoporation with distance. Anal Chem 2000, 72:1342-1347.

13. Stevenson DJ, Gunn-Moore FJ, Campbell P, Dholakia K: Transfection by Optical Injection. In Handbook of Photonics for Biomedical science. Edited by Tuchin W. Boca Raton: CRC Press, Taylor and Francis Group; 2010:87-118.

14. Kalies S, Heinemann D, Schomaker M, Escobar HM, Heisterkamp A, Ripken T, Meyer H: Plasmonic laser treatment for Morpholino oligomer delivery in antisense applications. J Biophotonics 2013, doi:10.1002/jbio.201300056

15. Heinemann D, Schomaker M, Kalies S, Schieck M, Carlson R, Murua Escobar H Ripken T, Meyer H, Hesterkamp A: Gold nanoparticle mediated laser transfection for efficient siRNA mediated gene knock down. PLoS One 2013, 8: doi:10.1371.

16. Schomaker M, Killian D, Willenbrock S, Heinemann D, Kalies S, Ngezahayo A, Nolte I, Ripken T, Junghanss C, Meyer H, Murua Escobar H, Hesterkamp A: Biophysical effects in off-resonant gold nanoparticle mediated (GNOME) laser transfection of cell lines, primary- and stem cells using fs laser pulses. J Biophotonics 2014, doi:10.1002/jbio.201400065.
17. Hashimoto S, Werner D, Uwada T: Studies on the interaction of pulsed lasers with plasmonic gold nanoparticles toward light manipulation, heat management, and nanofabrication. J Photoch Photobiol C 2012, 13:28-54.

18. Boulais E, Lachaine R, Meunier M: Plasma mediated off-resonance plasmonic enhanced ultrafast laser-induced nanocavitation. Nano Lett 2012, 12:4763-4769.

19. Nedyalkov NN, Imamova S, Atanasov PA, Tanaka Y, Obara M: Interaction between ultrashort laser pulses and gold nanoparticles: nanoheater and nanolens effect. J Nanopart Res 2011, 13:2181-2193.

20. Schomaker M, Fehlauer H, Bintig W, Ngezahayo A, Nolte I, Murua Escobar H, Lubatschowski H, Heisterkamp A: Fs-laser cell perforation using gold nanoparticles of different shapes. ProC SPIE 2010, 7589:75890C.

21. Schomaker M, Killian D, Willenbrock S, Diebbold E, Mazur E, Bintig W, Ngezahayo A, Nolte I, Murua Escobar H, Junghanß C, Lubatschowski H, Heisterkamp A: Ultrashort laser pulse cell manipulation using nano- and micro- materials. Proc SPIE 2010, 7762:77623G.

22. Baumgart J, Humbert L, Boulais É, Lachaine R, Lebrun JJ, Meunier M: Off-resonance plasmonic enhanced femtosecond laser optoporation and transfection of cancer cells. Biomaterials 2012, 33:2345-2350.

23. König K: Multiphoton microscopy in life sciences. J Microsc 2000, 200:83-104.

24. Schomaker M: Plasmonenbasierte Zelltransfektion im Hochdurchsatz mittels ultrakurzer Laserpulse. Garbsen, Germany: Degree Thesis, University Hannover, PZH Verlag; 2013.

25. Winkler S, Murua Escobar H, Meyer B, Simon D, Eberle N, Baumgartner W, Loeschke S, Nolte I, Bullerdiek J: HMGA2 expression in a canine model of prostate cancer. Cancer Genet Cytogenet 2007, 177:98-102.

26. Vogel A, Noack J, Hüttman G, Paltauf G: Mechanisms of femtosecond laser nanosurgery of cells and tissues. App/ Phys B 2005, 81:1015-1047.

27. Kuetemeyer K, Rezgui R, Lubatschowski H, Heisterkamp A: Influence of laser parameters and staining on femtosecond laser-based intracellular nanosurgery. Biomed Opt Express 2010, 1:587597.

28. Jee $Y$, Becker MF, Walser RM: Laser-induced damage on single-crystal metal surfaces. J Opt Soc Am B 1988, 5:648-659.

29. Ekici O, Harrison RK, Durr NJ, Eversole DS, Lee M, Ben-Yakar A: Thermal analysis of gold nanorods heated with femtosecond laser pulses. J App Phys D 2008, 41:1-11.

30. Pelton M, Aizpurua J, Bryant G: Metal-nanoparticle plasmonics. Laser Photon Rev 2008, 2:136-159.

31. Anisimov SI, Kapeliovich BL, Perel'man TL: Electron emission from metal surfaces exposed to ultrashort laser pulses. Soviet Physics JETP 1974, 39:375-377.

32. Jain PK, Lee KS, El-Sayed IH, El-Sayed MA: Calculated absorption and scattering properties of gold nanoparticles of different size, shape, and composition: applications in biological imaging and biomedicine. J Phys Chem B 2006, 110:7238-7248.

33. Chithrani BD, Ghazani AA, Chan WC: Determining the size and shape dependence of gold nanoparticle uptake into mammalian cells. Nano Lett 2006, 6:662-668.

34. Nel AE, Mädler L, Velegol D, Xia T, Hoek EM, Somasundaran P, Klaessig F, Castranova V, Thompson M: Understanding biophysicochemical interactions at the nano-bio interface. Nat Mater 2009, 8:543-557.

35. Pustovalov VK, Smetannikov AS, Zharov VP: Photothermal and accompanied phenomena of selective nanophotothermolysis with gold nanoparticles and laser pulses. Laser Phys Lett 2008, 5:775-792.

36. Bisker $G$, Yelin D: Noble-metal nanoparticles and short pulses for nanomanipulations: theoretical analysis. JOSA B 2012, 29:1383-1393.

37. Lukianova-Hleb E, Hu Y, Latterini L, Tarpani L, Lee S, Drezek RA, Hafner JH, Lapotko DO: Plasmonic nanobubbles as transient vapor nanobubbles generated around plasmonic nanoparticles. ACS Nano 2010, 4:2109-2123.

38. Lukianova-Hleb EY, Ren X, Constantinou PE, Danysh BP, Shenefelt DL, Carson DD, Farach-Carson MC, Kulchitsky VA, Wu X, Wagner DS, Lapotko DO: Improved cellular specificity of plasmonic nanobubbles versus nanoparticles in heterogeneous cell systems. Plos one 2012, 7:e34537.

39. Pitsillides CM, Joe EK, Wei $X$, Anderson RR, Lin CP: Selective cell targeting with light-absorbing microparticles and nanoparticles. Biophys J 2003, 84:4023-4032.

40. Zharov VP, Galitovsky V, Viegas M: Photothermal detection of local thermal effects during selective nanophotothermolysis. Appl Phys Lett 2003, 83:4897-4899.

41. Minai L, Yeheskely-Hayon D, Golan L, Bisker G, Dann EJ, Yelin D: Optical nanomanipulations of malignant cells: controlled cell damage and fusion. Small 2012, 8:1732-1739. 
42. Quinten M: Local fields close to the surface of nanoparticles and aggregates of nanoparticles. Appl Phys B 2001, 73:245-255.

43. Nedyalkov NN, Atanasov PA, Obara M: Near-field properties of a gold nanoparticle array on different substrates excited by a femtosecond laser. Nanotechnology 2007, 18:305703.

44. Skuridin SG, Dubinskaya VA, Rudoy VM, Dement'eva OV, Zakhidov ST, Marshak TL, Kuz'min VA, Popenko VI, Evdokimov YM: Effect of gold nanoparticles on DNA package in model systems. Dokl Biochem Biophys 2010, 432:141-143.

45. Ferhanoglu O, Yildirim M, Subramanian K, Ben-Yakar A: A 5-mm piezoscanning fiber device for high speed ultrafast laser microsurgery. Biomed Opt Express 2014, 5:2023-2036.

46. Ma N, Gunn-Moore F, Dholakia K: Optical transfection using an endoscope-like system. J Biomed Opt 2011, 16:028002.

47. Lukianova-Hleb EY, Ren X, Sawant RR, Wu X, Torchilin VP, Lapotko DO: On-demand intracellular amplification of chemoradiation with cancer-specific plasmonic nanobubbles. Nat Med 2014, 20:778-784.

48. Watanabe S, Ueda Y, Akaboshi S, Hino Y, Sekita Y, Nakao M: HMGA2 maintains oncogenic RAS-induced epithelial-mesenchymal transition in human pancreatic cancer cells. Am J Pathol 2009, 174:854-868.

49. Withrow JS, Vail DM: Withrow and MacEwen's Small Animal Clinical Oncology. 5th ed. St Louis Missouri: Saunders Company; 2012.

50. Davis AA, Farrar MJ, Nishimura N, Jin MM, Schaffer CB: Optoporation and genetic manipulation of cells using femtosecond laser pulses. Biophys J 2013, 105:862-871.

51. Murua Escobar H, Meyer B, Richter A, Becker K, Flohr AM, Bullerdiek J, Nolte I: Molecular characterization of the canine HMGB1. Cytogenet Genome Res 2003, 101:33-38.

52. Winkler S, Murua Escobar H, Eberle N, Reimann-Berg N, Nolte I, Bullerdiek J: Establishment of a cell line derived from a canine prostate carcinoma with a highly rearranged karyotype. J Hered 2005, 96:782-785.

53. Haase A, Olmer R, Schwanke K, Wunderlich S, Merkert S, Hess C, Zweigerdt R, Gruh I, Meyer J, Wagner S, Maier LS, Han DW, Glage S, Miller K, Fischer P, Schöler HR, Martin U: Generation of induced pluripotent stem cells from human cord blood. Cell stem cell 2009, 5:434-441.

54. Schneider CA, Rasband WS, Eliceiri KW: NIH Image to ImageJ: 25 years of image analysis. Nat Methods 2012, 9:671-675.

55. Lin Z, Zhigilei LV, Celli V: Electron-phonon coupling and electron heat capacity of metals under conditions of strong electron-phonon nonequilibrium. Phys Rev B 2008, 77:075133.

56. Draine BT, Flatau PJ: Discrete-dipole approximation for scattering calculations. J Opt Soc Am A 1994, 11:1491-1499.

57. Draine, BT, Flatau PJ: User Guide to the Discrete Dipole Approximation Code DDSCAT 7.2. 2012

58. Keldysh LV: lonization in the field of a strong electromagnetic wave. J Exptl Theoret Phys (USSR) 1964, 47:1945-1957. translation: Soviet Physics JETP 1965, 20: 1307-1314.

\section{Submit your next manuscript to BioMed Central and take full advantage of:}

- Convenient online submission

- Thorough peer review

- No space constraints or color figure charges

- Immediate publication on acceptance

- Inclusion in PubMed, CAS, Scopus and Google Scholar

- Research which is freely available for redistribution 